\title{
Character Displacement in Sphaeroma spp. (Isopoda: Crustacea). I. Field Evidence
}

\author{
J. O. Frier \\ Institute of Ecology and Genetics, University of Aarhus, Ny Munkegade, DK-8000 Aarhus C, Denmark
}

\begin{abstract}
Differences have been demonstrated in body size and reproductive periods of sympatric and allopatric populations of the isopods Sphaeroma hookeri Leach and S. rugicauda Leach. S. rugicauda is bigger and S. hookeri smaller in sympatry than in allopatry. This results partly from a divergent displacement of the life cycles of these annual isopods, and partly from a divergent displacement of the size of the molt stages. Special attention has been given to the borders between allopatric and sympatric populations, where isopod size is intermediate between that of the neigboring populations
\end{abstract}

\section{INTRODUCTION}

Sympatric species which differ only with respect to one niche dimension are often evenly spaced within that dimension (Hutchinson, 1959; Schoener, 1965). This phenomenon has been termed character difference' and attributed to a minimization of interspecific competition attained by means of individual selection. From this principle, differences in characters between sympatric and allopatric populations of the same species within the guild can be deduced and illustrated (Brown and Wilson, 1956). This phenomenon has been termed 'character displacement' (Brown and Wilson, 1956).

Over the last 20 years other papers have contributed some observational evidence to the theory of character displacement (Parkes, 1965; Ashmole, 1968; Ficken et al., 1968; Cody, 1969; Blair, 1974; Huey and Pianka, 1974; Nursall, 1974; Walker, 1974), but there still exists a need for in-depth investigations providing enough material for a reliable test of the hypothesis. Grant (1975) analysed the classical case of character displacement between the two species of nuthatches (Sitta tephronota and S. neumayer) and found significant evidence for reproductive character displacement. Fenchel (1975b) and Fenchel and Kofoed (1976), studying the very abundant species of mudsnails, Hydrobia ulvae and $H$, ventrosa, illustrated character displacement in relation to food exploitation.

Ideally, an analysis of this phenomenon should include three different types of investigation: field evidence showing character displacement; experiments documenting the advantage of the displacement in terms of individual fitness; and evidence for the hereditability of the displaced characters. This paper focuses on field evidence for character displacement of body size and breeding time in two sibling species of isopods, Sphaeroma hookeri and S. rugicauda. Two following papers (Frier, in preparation) will deal with experimental studies on the ecological effects of character displacement and the hereditability of the studied characters.

The two species of isopods are highly suitable for the study of character displacement. They have a very flexible life cycle, wide variation in some of the important growth parameters (Frier, 1976), are abundant in their habitats, and easy to maintain in the laboratory. In addition much has been written about these isopods, especially with respect to population genetics, physiology, and ecology (for references; see Frier, 1978).

\section{MATERIALS AND METHODS}

Like many other abundant littoral crustaceans, Sphaeroma hookeri and S. rugicauda are omnivorous. Their major food source is decaying plant material and diatoms. The life cycle of these isopods, extensively described by Kinne (1954), Jensen (1955), and Harvey (1969), includes in North European waters two annual 
broods, the first and most numerous at the beginning of the summer, the second in the fall. The main predation pressure on both species results from small fish.

The isopods were collected at 47 stations (each about $100 \times 100 \mathrm{~m}$ ) in 11 major areas from inner Danish waters (Fig. 1). At each station collections were made during September in the three successive years 1975 , 1976, and 1977; 200 individuals were collected at each sampling. When a station could not yield $3 \times 200$ individuals, the data were excluded from the analysis.

Fucus spp. and sand harbored similiar-sized isopods within each sampling station, and these were the substrates consequently used for sampling. All isopods caught were concentrated on a $375-\mu \mathrm{m}$ sieve, which retains even the smallest individuals

The isopods were identified according to Jensen (1955), and their total length measured by means of an ocular micrometer. In order to identify the various female molt stages, individuals with 1,2, or 3 oostegite precursors were classified into three groups. Gravid females comprised a fourth group, and post-gravid females a fifth. Groups 1 and 2 were eventually pooled due to their great similarity.

In sympatric populations, the sizes of the two species could be directly compared. In allopatric populations, however, where comparative size differences could be due to location and inheritance, this is not possible. To solve this problem, a comparative variance analysis on the size of the sympatric and allopatric populations of each species was made.

Breeding time, i. e., the period in which the newly hatched young appear, was determined in the laboratory. Gravid females from the various stations were placed in tanks and the number of young appearing were counted at 2-day intervals. Duration of the gravidity period was recorded on 50 females of each species and then averaged. The experiment was carried out at approximately average temperature for the field stations at that time of the year $\left(19.5^{\circ} \mathrm{C}\right)$.

\section{RESULTS}

In areas of Sympatry, Sphaeroma hookeri is of smaller and $S$. rugicauda of larger average size, than in areas of allopatry (Figs. 1 and 2; Table 1). Based on the average isopod size at each station, the probability of

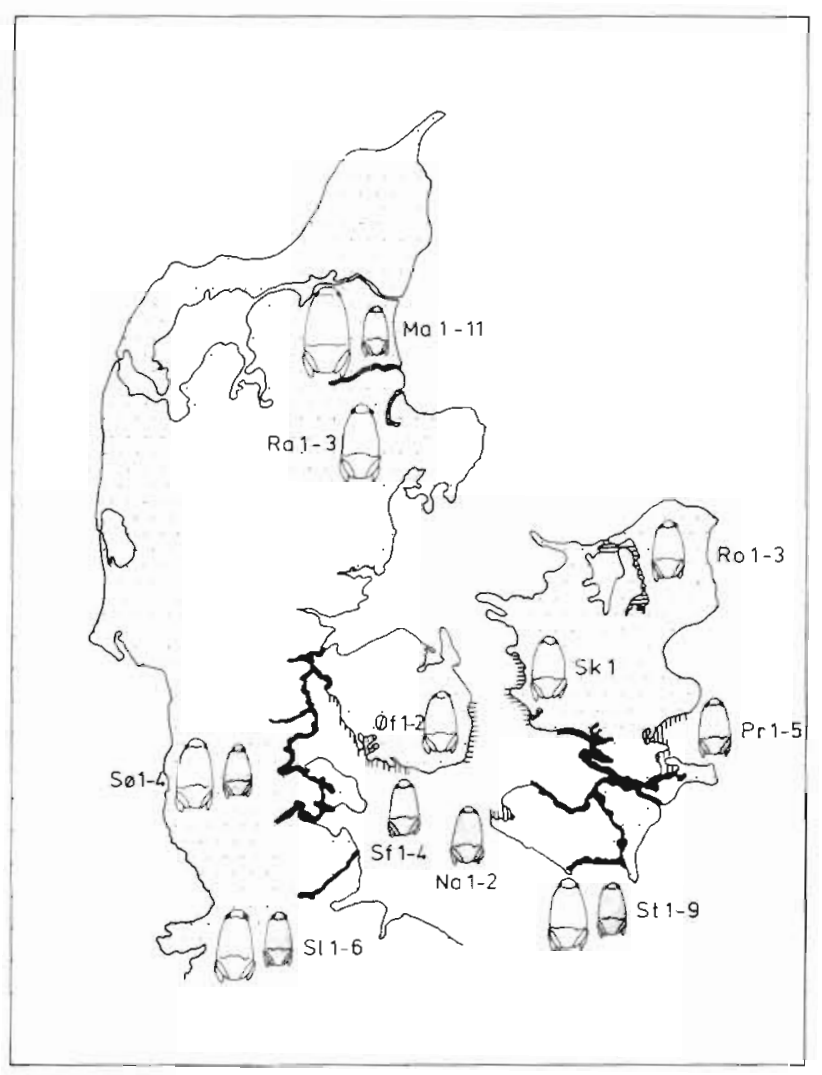

Fig. 1. Distribution of sampling areas. Isopod sizes are proportional to real size differences in September. White: Sphaeroma rugicauda; dotted: S. hookeri. Areas with horizontal hatching harbor allopatric S. rugicauda. Coastal areas with vertical hatching harbor allopatric $S$. hookeri; black designates areas where the two species are sympatric

Table 1. Sphaeroma rugicauda (S.r.) and S. hookeri (S.h.). Comparisun of body size between areas of sympatry and neighboring areas of allopatry

\begin{tabular}{|c|c|c|c|c|c|c|c|}
\hline \multirow[t]{3}{*}{ Area and species } & & \multirow{2}{*}{\multicolumn{2}{|c|}{$\begin{array}{l}\text { Body size (natural logarithm of } \\
\text { length in } \mathrm{mm} \pm \text { st. dev.) }\end{array}$}} & \multicolumn{4}{|c|}{ Size difference and proportions } \\
\hline & & & & \multicolumn{2}{|c|}{ (In length, mm) } & \multicolumn{2}{|c|}{ quotient } \\
\hline & & sympatric & allopatric & sympath. & allop. & sympat. & allop. \\
\hline \multirow[t]{2}{*}{ Sonderjylland } & S.r. & $1.639 \pm 0.170$ & $1.606 \pm 0.166$ & & & & \\
\hline & S.h. & $1.379 \pm 0.182$ & $1.493 \pm 0.160$ & 0.26 & 0.11 & 1.3 & 1.1 \\
\hline \multirow[t]{2}{*}{ Slien } & S.r. & $1.674 \pm 0.165$ & $1.606 \pm 0.166$ & & & & \\
\hline & S.h. & $1.444 \pm 0.199$ & $1.493 \pm 0.160$ & 0.23 & 0.11 & 1.3 & 1.1 \\
\hline \multirow[t]{2}{*}{ Storstrømmen } & S.r. & $1.675 \pm 0.163$ & $1.527 \pm 0.208$ & & & & \\
\hline & S.h. & $1.430 \pm 0.174$ & $1.503 \pm 0.160$ & 0.25 & 0.03 & 1.3 & 1.0 \\
\hline \multirow[t]{2}{*}{ Mariager } & S.r. & $1.875 \pm 0.179$ & $1.726 \pm 0.196$ & & & & \\
\hline & S.h. & $1.323 \pm 0.152$ & & 0.55 & & 1.7 & \\
\hline
\end{tabular}




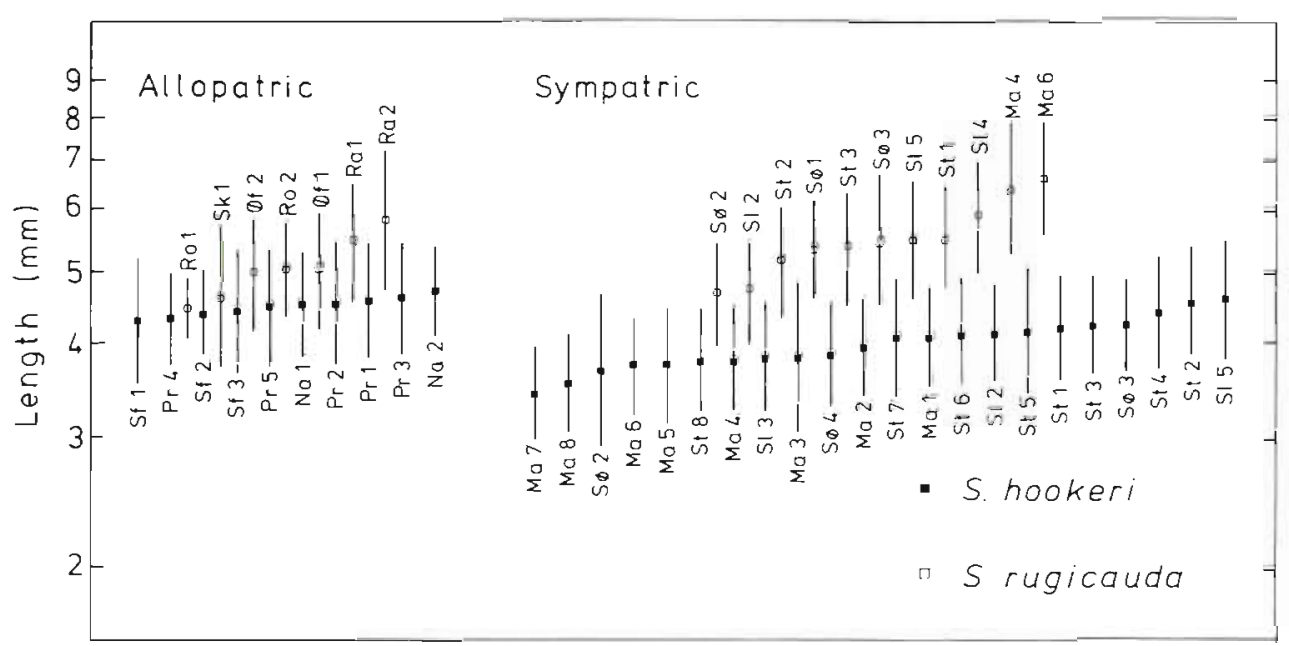

Fig. 2. Sphaeroma hookeri and S. rugicauda. Mean size and standard deviation in September. Stations are ranked according to mean body size. All values represent mean of measurements through three successive years. Only stations which yielded 200 individuals in each of these years are included. For explanation of abbreviated area code see legend to Figure 1

S. rugicauda being larger and $S$. hookeri smaller in sympatry as a result of chance events is 10 and $0.1 \%$, respectively. The most isolated population in Mariager Fjord (Ma) is also the population in which the displacement is greatest.

The degree of size displacement in one of the two species is hypothesized to be dependent on population

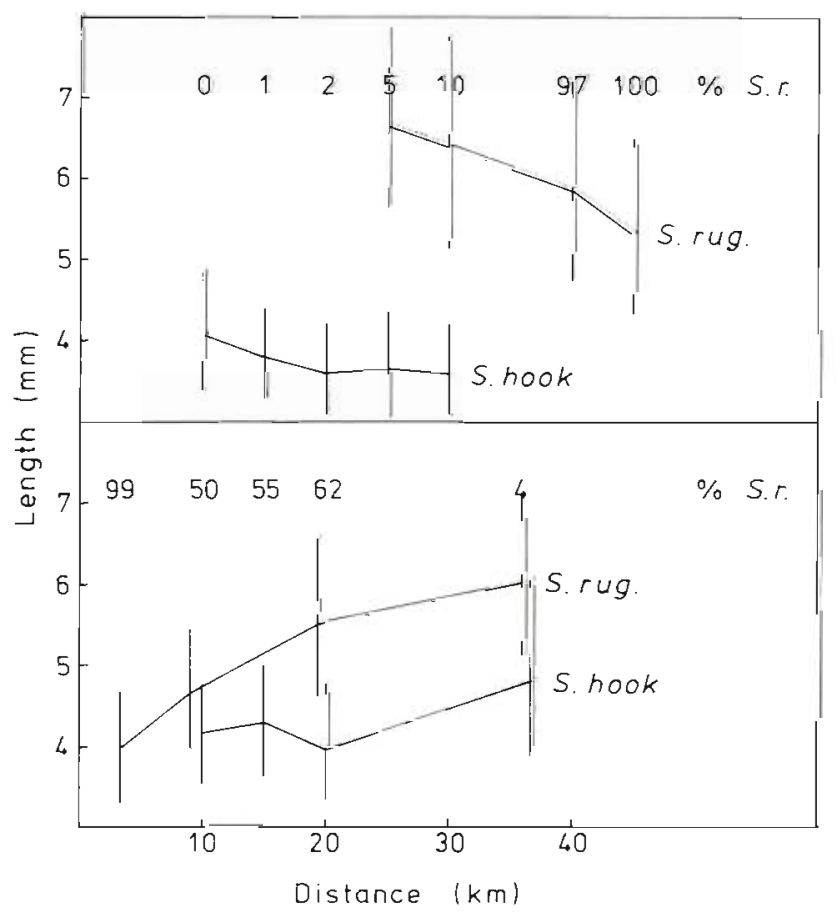

Fig. 3. Sphaeroma hookeri and S. rugicauda. Sizes of isopods in Mariager Fjord (upper part of figure) and Slien compared with relative abundances and distances from the innermost part of the fjord. $\%$ S. $r$. designates the percentage of $S$. rugicauda present in each Sphaeroma sample size of the other species in such a way that the rarer species is displaced more. In Slien (Sl), where Sphaeroma rugicauda dominates the Sphaeroma samples from the inner part, and $S$. hookeri the samples from the outer part of the fjord, $S$. hookeri is displaced most in the inner part (being smaller) and S. rugicauda most on the outer part (being larger). In Mariager Fjord, where the inward/outward distribution of the two Sphaeroma species is reversed, this trend in their sizes is also reversed (Fig. 3).

It is important to determine whether these size displacements result from a displacement in life cycles. Table 2 shows the average size of the recognizable molt stages, in which there is a significant size displacement regardless of the displacement in breeding time (Table 3). Mating time (calculated from the duration of pregnancy: 35 days in Sphaeroma hookeri and 49 days in $S$. rugicauda, and from breeding time) is also displaced. The overlap, that is the fraction of matings occurring simultaneously in the two species of all matings, is only $2 \%$ in sympatric populations, while it is $10 \%$ in allopatric ones.

Both species spawn in summer and fall. Females from all populations spawn in summer, but this is not the case in fall, suggesting some general advantage in summer breeding within these species. In allopatric Sphaeroma hookeri, $25 \%$ (average of 10 populations) of the females spawn in fall, but this is true of only $1 \%$ in the sympatric populations.

\section{DISCUSSION}

The present paper demonstrates character displacement in Sphaeroma species. Sympatry is correlated 
Table 2. Sphaeroma rugicauda and $S$. hookeri. Differences in size of 4 molting stages between sympatric and allopatric populations. Stage 1: first prepubescent stage; Stage 2: second prepubescent stage; Stage 3: gravid stage; Stage 4: first postgravid stage

\begin{tabular}{|llccrrr}
\hline Species & Habitat & Stage & $\begin{array}{c}\text { Length } \\
\text { (mm) }\end{array}$ & In length & St. dev. \\
\hline S. rugicauda & Allop. & 1 & 4.84 & 1.577 & 0.101 & 218 \\
S. rugicauda & Sympat. & 1 & 5.19 & 1.647 & 0.095 & 72 \\
S. hookeri & Allop. & 1 & 4.21 & 1.437 & 0.090 & 189 \\
S. hookeri & Sympat. & 1 & 4.05 & 1.399 & 0.103 & 600 \\
S. rugicauda & Allop. & 2 & 5.65 & 1.732 & 0.084 & 190 \\
S. rugicauda & Sympat. & 2 & 5.90 & 1.775 & 0.078 & 83 \\
S. hookeri & Allop. & 2 & 4.91 & 1.591 & 0.106 & 96 \\
S. hookeri & Sympat. & 2 & 4.77 & 1.562 & 0.109 & 285 \\
S. rugicauda & Allop. & 3 & 6.08 & 1.804 & 0.094 & 721 \\
S. rugicauda & Sympat. & 3 & 6.30 & 1.841 & 0.122 & 156 \\
S. hookeri & Allop. & 3 & 5.21 & 1.651 & 0.119 & 892 \\
S. hookeri & Sympat. & 3 & 5.03 & 1.615 & 0.102 & 275 \\
S. hookeri & Allop. & 4 & 5.97 & 1.787 & 0.093 & 141 \\
S. hookeri & Sympat. & 4 & 5.74 & 1.747 & 0.085 \\
\hline
\end{tabular}

Table 3. Sphaeroma rugicauda and S. hookeri. Difference in breeding time between sympatric and allopatric populations. For station abbreviations consult Figure 1

\begin{tabular}{|c|c|c|c|c|c|c|c|c|}
\hline \multicolumn{3}{|c|}{ Sphaeroma hookeri } & \multicolumn{6}{|c|}{ Sphaeroma rugicauda } \\
\hline \multirow{2}{*}{$\begin{array}{l}\text { Station } \\
\operatorname{Pr} 1\end{array}$} & \multirow{2}{*}{$\begin{array}{r}\text { Habitat } \\
\text { Allop. }\end{array}$} & \multirow{2}{*}{$\begin{array}{c}\begin{array}{c}\text { Breeding time } \\
\text { st. dev. (days) }\end{array} \\
14 / \text { VII } \pm 5.8\end{array}$} & \multicolumn{3}{|c|}{$\begin{array}{l}\text { Calculated } \\
\text { mating time }\end{array}$} & \multirow{2}{*}{$\begin{array}{c}\begin{array}{c}\text { Breeding time } \\
\text { st. dev. (days) }\end{array} \\
17 / \text { VII } \pm 6.2\end{array}$} & \multirow{2}{*}{$\begin{array}{l}\text { Habitat } \\
\text { Allop. }\end{array}$} & \multirow{2}{*}{$\begin{array}{l}\text { Station } \\
\text { Ro. } 1\end{array}$} \\
\hline & & & $9 / \mathrm{VI}$ & $28 / 5$ & $\mathrm{~V}$ & & & \\
\hline PI 6 & Allop. & $12 / \mathrm{VII} \pm 6.0$ & $7 / \mathrm{VI}$ & $23 / 5$ & V & $12 / \mathrm{VII} \pm 5.5$ & Allop. & Ro. 3 \\
\hline & & & & $21 / 5$ & $\mathrm{~V}$ & $10 /$ VII \pm 4.8 & Allop. & Sk. 1 \\
\hline Ma. 7 & Symp. & $15 /$ VII \pm 4.3 & $10 / \mathrm{VI}$ & $19 / 5$ & $\mathrm{~V}$ & $8 /$ VII \pm 5.6 & Symp. & Ma.7 \\
\hline
\end{tabular}

with changes in characters compared with allopatric ones. The functional significance and the hereditability of the characters concerned is the subject of future publications.

A significant size displacement of sympatric Sphaeroma has been demonstrated. The evidence for the displacement in $S$. hookeri is stronger than for $S$. rugicauda. This is due to the greater variance between different populations of the latter species, and to the great number of $S$, hookeri populations sampled.

In contrast to most previous studies of character displacement (see however Fenchel, 1975) the present study demonstrates the reproducability of the phenomenon, that is, several cases of sympatry and allopatry have been studied. This allows for a statistical evaluation of the chance that the changes found have arisen from causes unrelated to sympatry. As shown, such probability is very low and of the order $0.01 \%$. Comparison between the clines in Slien and in Mariager Fjord also provides strong evidence that the displacements found are correlated with sympatry.
In general, the difference between the major field areas is most important (Table. 1) because there is less interference from migration. In all cases, the populations occurring on borders between sympatric and allopatric areas show intermediate sizes. These gradual changes are a logical consequence of migration in these areas. Here the amount of displacement shown by a certain species is inversely correlated with its relative abundance; i. e., as the isopods approach $100 \%$ abundance, they approach allopatric size.

Among the characteristics usually studied are, besides size differences, the reproductive periods (Christiansen and Fenchel, 1977). While the former could be a secondary result of the latter, the analysis of the present data shows that both kinds of displacement have taken place independently. The finding that the species which becomes the largest in sympatry tends to reproduce earlier, and the species which becomes the smallest in sympatry tends to reproduce later is in accordance with a generalisation of Hutchinson (1959) based on sympatric species of the water bug genus 
Corixa, since this will retain a constant size ratio throughout the life cycle.

The present study resembles Fenchel's (1975a, b) study of the prosobranch species Hydrobia ulvae, $H$. ventrosa and $H$. neglecta in that congeners with somewhat displaced but overlapping habitat preferences have been studied. The Sphaeroma species examined, however, exibit smaller differences between habitat preferences, and these are less well understood (Frier, 1976, 1978). Sphaeroma hookeri tends to thrive better at a constant and low salinity; this is in accordance with the distributional pattern in most areas. In Slien, however, $S$. rugicauda dominates the inner and most brackish part of the fjord. The reason for this is perhaps that $S$. rugicauda, being capable of going on land in periods of anoxia, better withstands the very eutrophic conditions in the inner part of this fjord (Frier, unpublished). At any rate, the actual distribution pattern and the lack of obvious correlations with abiotic factors suggest that interspecific interactions are important.

Differences in size and reproductive pattern may imply several functional and ecological mechanisms, viz., reproductive isolation in the cases where interspecific mating is avoided in this manner (reproductive character displacement), and differences in utilization of food resources or shelters (exploitative character displacement; see Christiansen and Fenchel, 1977). An interpretation of the selective forces which actually resulted in the present findings is not possible on the basis of field evidence alone.

Acknowledgement. I would like to thank Professor T Fenchel for introducing me to the problem, for encouraging discussions, and for help in many other ways.

\section{LITERATURE CITED}

Ashmole, N. P. (1968). Body size, prey size, and ecological segregation in five sympatric tropical terns (Aves: Laridae). Syst. Zool., 17, 292-309.

Blair, W. F. (1974). Character displacement in frogs. Am. Zool., 14, 1119-1125
Brown, J. and Wilson, E. O. (1956). Character displacement. Syst. Zool., 5, 49-64.

Christiansen, F. B. and Fenchel, T M. (1977). Theories of Populations in Biological Communities, Springer-Verlag, Berlin.

Cody, M. L. (1969). Convergent characteristics in sympatric populations, a possible role to interspecific territoriallity. Condor, 71, 222-239.

Fenchel, T (1975a). Factors determining the distribution pattern of mud snails (Hydrobidae). Oecologia, 20,1-17.

Fenchel, T. (1975b). Character displacement and coexistence in mud snails (Hydrobidae). Oecologia, 20, 19-32.

Fenchel, T. and Kofoed, L. H. (1976). Evidence for exploitative interspecific competition in mud snails (Hydrobidae). Oikos, 27, 367-376

Ficken, R. W., Ficken, M. S., Morse, D. H. (1968). Competition and character displacement in two sympatric pine-dwelling warblers (Dendroica, Parulidae). Evolution, Lawrence, Kansas, 22, 307-314.

Frier, J. O. (1976). Oxygen consumption and osmoregulation. in the isopods Sphaeroma hookeri Leach and Sphaeroma rugicauda Leach. Ophelia, 15, 193-203.

Frier, J. O. (1978). En sammenlignede undersøgelse af økologien hos to danske Sphaeroma arter. Ph. D. thesis, University of Aarhus.

Grant, P. R. (1975). The classical case of character displacement. Evol. Biol., 8, 237-337.

Harvey, C. E. (1969). Breeding and distribution of Sphaeroma (Crustacea, Isopoda) in Britain. J. Anim. Ecol., 38, 399-406.

Huey, F. and Pianka, E. R. (1974). Ecological character displacement in a lizard. Amer. Zool., 14, 1127-1136.

Hutchinson, G. E. (1959). Homage to Santa Rosalia or why there are so many kinds of animals. Am. Nat., 93, 145-159.

Jensen, J. P. (1955). Biological observations on the isopod Sphaeroma hookeri Leach. Vidensk. Meddr. dansk naturh. Foren., 117, 305-339.

Kinne, O. (1954). Eidomie, Anatomie und Lebenszyklus von Sphaeroma hookeri Leach (Isopoda). Kieler Meeresforsch., 10, 100-120.

Nursall, J. R. (1974). Character displacement and fish behaviour especially in coral reef communities. Am. Zool., $14,1099-1119$.

Parkes, K. S. (1965). Character displacement in some Philipine cuckoos. The living bird, 4 th annual report of the Comell laboratory of ornithology. pp. 89-98.

Schoener, T. W. (1965). The evolution of bill size differences among sympatric congeneric species of birds. Evolution, Lawrence, Kansas, 19, 189-213.

Walker, T. J. (1974). Character displacement and acoustic insects. Am. Zool., 14, 1137-1150. 